\title{
Comprehensive evaluation of FKBP10 expression and its prognostic potential in gastric cancer
}

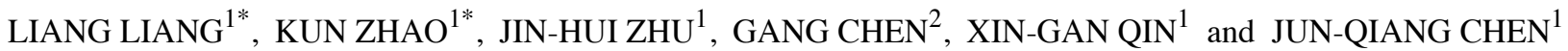 \\ Departments of ${ }^{1}$ Gastrointestinal Surgery and ${ }^{2}$ Pathology, The First Affiliated Hospital of Guangxi Medical University, \\ Nanning, Guangxi Zhuang Autonomous Region 530021, P.R. China
}

Received November 23, 2018; Accepted May 31, 2019

DOI: $10.3892 /$ or.2019.7195

\begin{abstract}
FK506 binding protein 10 (FKBP10) has been reported to be dysregulated in numerous types of cancer; however, few reports have investigated FKBP10 in gastric cancer (GC). The aim of the present study was to investigate FKBP10 expression in GC and to analyze its association with the prognosis of patients with GC. FKBP10 mRNA expression was evaluated using The Cancer Genome Atlas (TCGA) and Gene Expression Omnibus (GEO) databases. The standardized mean differences of the meta-analysis were comprehensively evaluated for FKBP10 expression from a series of GEO datasets. Kaplan-Meier survival and Cox regression analyses were applied to predict the prognostic value of FKBP10 in patients with GC. Additionally, the protein expression levels of FKBP10 were validated by immunohistochemistry (IHC) in $40 \mathrm{GC}$ and adjacent tissues. FKBP10 co-expression network and bioinformatics analyses were then used to explore the potential functional mechanisms of FKBP10. The results revealed that the mRNA expression levels of FKBP10 were significantly increased in GC within the TCGA and GEO databases. Survival analysis revealed that high FKBP10 expression results in poorer overall survival and disease-free survival $(\mathrm{P}<0.05)$. Multivariate cox regression analysis indicate FKBP10 as a dependent prognostic factor. The results of IHC indicated that the protein expression levels of FKBP10 were higher in GC tissues than in adjacent non-GC tissues $(\mathrm{P}<0.001)$. Co-expression networks and functional enrichment analysis suggested that FKBP10 may be involved in the development of GC via cell adhesion molecules and extracellular matrix-receptor interaction pathways. Therefore, the findings of the present study indicated that FKBP10 is upregulated in GC tissues, and suggests its potential
\end{abstract}

Correspondence to: Professor Jun-Qiang Chen, Department of Gastrointestinal Surgery, The First Affiliated Hospital of Guangxi Medical University, 6 Shuangyong Road, Nanning, Guangxi Zhuang Autonomous Region 530021, P.R. China

E-mail:gxhans@163.com

*Contributed equally

Key words: FK506 binding protein 10, gastric cancer, prognosis, The Cancer Genome Atlas, Gene Expression Omnibus prognostic value. Therefore FKBP10 may be a potential therapeutic target for the treatment of GC.

\section{Introduction}

Gastric cancer (GC) is a common malignancy worldwide. The incidence of GC is highest in East Asian countries, including Korea, Mongolia, Japan and China, with 40-60 cases per 100,000 individuals, followed by Eastern Europe ( 35 cases per 100,000 people) $(1,2)$. According to a statistical report, there were $\sim 679,000$ new cases of GC and 498,000 associated mortalities in China in 2015 (3). Current treatments for GC include surgery, chemotherapy, radiation and immunotherapy, all of which can be administered alone or in combination (4). Adjuvant treatment has been shown to be beneficial for GC $(4,5)$. In Japan, early diagnosis via endoscopy and early tumor resection are used to improve the 5-year survival rate of patients with GC $(5,6)$. Those with GC often present symptoms only in the later stages; however, the majority of patients do not receive medical attention until symptoms present. At the time of definitive diagnosis, many patients with GC are of an advanced stage of disease, at which point treatment is less effective. Despite advancements in treatment, no significant improvement in the prognosis of patients with GC have been reported; the 5-year overall survival rate was determined to be $30-35 \%$ (7). Thus, highly sensitive biomarkers to increase the sensitivity of early diagnostic methods for GC are of great interest for the development high-specificity drugs.

FK506 binding protein (FKBP65) is a $65-\mathrm{kDa}$ protein and highly conserved; almost all FKBP family members have peptide precursor cis-trans isomerase activity (8). FKBP prolyl isomerase 10 (FKBP10) is a gene encoding FKBP65, and is a member of a group of proteins termed the immunophilins, belonging to the FKBP-type peptidylprolyl cis/trans isomerase family $(9,10)$. It is located in the endoplasmic reticulum, and is a molecular chaperone that interacts with collagen (11); FKBP10 has been reported to directly interact with collagen I (11). As an important intracellular regulatory factor for extracellular matrix (ECM) reconstruction, FKBP10 is an important potential target for the treatment of idiopathic pulmonary fibrosis $(12,13)$. In addition, it is increasingly apparent that FKBP members serve a very important role in the formation of tumors and may be considered as novel biomarkers of cancer $(14,15)$. For example, FKBP10 is 
associated with ovarian cancer $(16,17)$, lung cancer (18), prostate cancer (19), leukemia (20), renal cell carcinoma (21) and colorectal cancer (22).

In recent years, numerous studies have identified genes related to the prognosis of GC (23-25). Some of these genes can act as prognostic factors for $\mathrm{GC}$, yet the prognostic potential of these genes as biomarkers in GC remains unknown. The importance of differentially expressed FKBP10 in GC and its prognostic value in patients with $\mathrm{GC}$ require further investigation.

In the present study, the differential expression levels of FKBP10 mRNA in GC and normal tissues were compared using the Gene Expression Omnibus (GEO) and The Cancer Genome Atlas (TCGA) databases; the removal of batch effects on same type platforms was performed in our GEO analysis. In addition, Kaplan-Meier survival and cox regression analyses were conducted to explore the potential prognostic value of FKBP10 expression in patients with GC.

\section{Materials and methods}

Data extraction of FKBP10 expression from GEO and TCGA databases. The data were limited to microarray and RNA sequencing uploaded before August 2018. Mesh-terms and free words were used for increasing the search parameters in the GEO databases (https://www.ncbi.nlm.nih.gov/geo/). The search terms were: 'Cancer', 'tumor', 'carcinoma' or 'neoplasm', and 'gastric' or 'stomach'. 'Homo sapiens' was used to limit the search range. In total, 20 microarrays containing 957 samples of GC and 536 samples of paracancer tissues with FKBP10 expression information were downloaded (Table I). The normalized expression value and the median expression value were obtained from multiple probes of FKBP10. The data of FKBP10 expression from the TCGA database (https://www.cancer.gov/about-nci/organization/ccg/research/structural-genomics/tcga) were downloaded with University of Santa Cruz Xena (https://xena.ucsc.edu/), which provided a normalized count of gene-level transcription.

Detection of FKBP10 mRNA expression levels in gastric cancer. To investigate the expression of FKBP10, Gene Expression Profiling Interactive Analysis (GEPIA) (26) was used to retrieve expression data of GC tissues. In addition, data on FKBP10 expression in 1,000 cell lines were provided by The Cancer Cell Line Encyclopedia (https://portals.broadinstitute.org/ccle). Except for the TCGA data, FKBP10 expression was obtained from a microarray series GEO dataset. After comparing FKBP10 expression in single series datasets, same-type microarray platforms were combined to expand sample capacity, in order to comprehensively analyze the expression of FKBP10. The removal of batch effects across platforms was performed using the 'sva' Bioconductor package of R (v3.5.0) (26). The standardized mean difference (SMD) method was used to assess the continuous variable, FKBP10 expression. Data from 19 gene microarrays were combined with a random effects model when heterogeneity $\left(\mathrm{I}^{2}\right)>50 \%$. The results were presented as forest plots. Sensitivity analyses and publication bias were used to evaluate the combined quality. Continuous variables of FKBP10 expression were converted to true positive, false positive, false negative and true negative counts. Summary receiver operating characteristic (SROC) of
19 GEO microarrays were used to comprehensively investigate the diagnostic value of FKBP10. All analyses were conducted using STATA 12.0 software (StataCorp). The associations between FKBP10 expression and certain clinicopathological parameters were analyzed using a Student's t-test. Tumor and paracancerous samples from the same patient were analyzed using a paired t-test, while an unpaired t-test was used to analyze unpaired samples. Genetic alterations of FKBP10 were determined by cBioPortal (https://www.cbioportal.org/). The DNA methylation information of FKBP10 was obtained from the MethHC database (http://methhc.mbc.nctu.edu.tw/) (27).

Prognosis analysis of FKBP10 in GC. We aimed to investigate the prognostic potential of FKBP10 in GC in the TCGA and GEO databases independently. Overall survival (OS) and disease-free survival (DFS) curves were drawn based on data from TCGA and GEO (28) via GEPIA (http://gepia. cancer-pku.cn/) and Kaplan-Meier Plotter (http://kmplot. com/analysis/) (29). Univariate and multivariate cox analyses were conducted with adjustments to age, sex, tumor stage, histological grade and the clinical features of GC.

Detection of FKBPIO protein expression by immunohistochemistry. The immunohistochemistry results of FKBP10 from the Human Protein Atlas (HPA) were investigated, which contained protein expression profiles as determined by immunohistochemistry (https://www.proteinatlas.org/) (30). In addition, immunohistochemistry data were verified using GC tissue and paired adjacent normal mucosa tissue samples. In total, 40 cases of GC tissue and adjacent normal tissue samples (20 male and 20 female, age range 25-79 years; average age 56.8-yars old) were collected from patients with GC at The First Affiliated Hospital of Guangxi Medical University (Nanning, China), between January 2018 and August 2018. The present study was approved by the Ethics Committee of The First Affiliated Hospital of Guangxi Medical University and all patients provided written informed consent. Antigen retrieval was conducted by boiling tissue sections in sodium citrate buffer (pH 6.0) at $100-120^{\circ} \mathrm{C}$ for $5 \mathrm{~min}$; endogenous peroxidase activity was blocked with $3 \%$ hydrogen peroxide at room temperature for $10 \mathrm{~min}$; sections were then incubated with a rabbit anti-FKBP10 polyclonal antibody (bs-13175R; 1:700; BIOSS) overnight at $4^{\circ} \mathrm{C}$, followed by a conjugated secondary antibody (cat. no. D-3004-15, Shanghai Long Island Biotec, Co., Ltd.) at room temperature for $30 \mathrm{~min}$; followed by $3^{\prime}, 3^{\prime}$-diaminobenzidene staining at room temperature for $5 \mathrm{~min}$. The average score was calculated by randomly selecting five fields under a light microscope (magnification x200). The immunoreaction score (IRS) was calculated according to the intensity of staining and the percentage of positive cells. Intensity was scored as follows: 0 , negative; 1 , weak; 2 , moderate and 3 , strong. The percentage of positive cells was scored as follows: $<5 \%, 0$; $6-25 \%, 1 ; 26-50 \%, 2 ; 51-75 \%, 3 ;>76 \%, 4$.

FKBP10 biological function analysis. To further investigate the biological function of FKBP10 in GC, we analyzed the possible interactions of FKBP10 using a protein-protein interaction (PPI) network. An interaction score of 0.4 was set as a cut-off value. In addition to PPI analysis, we identified the genes associated with FKBP10 expression that may also be involved 
Table I. Information of elected Gene Expression Omnibus series dataset.

\begin{tabular}{|c|c|c|c|c|}
\hline \multirow[b]{2}{*}{ ID } & \multirow[b]{2}{*}{ Type } & \multirow[b]{2}{*}{ Country } & \multicolumn{2}{|c|}{ Case } \\
\hline & & & GC & non-GC \\
\hline GSE29272 & GPL96 & USA & 134 & 134 \\
\hline GSE37023 & GPL96 & Singapore & 112 & 39 \\
\hline GSE54129 & GPL570 & China & 111 & 21 \\
\hline GSE64951 & GPL570 & USA & 63 & 31 \\
\hline GSE13911 & GPL570 & Italy & 38 & 31 \\
\hline GSE19826 & GPL570 & China & 12 & 15 \\
\hline GSE79973 & GPL570 & China & 10 & 10 \\
\hline GSE51725 & GPL570 & Japan & 8 & 2 \\
\hline GSE27342 & GPL5175 & USA & 80 & 80 \\
\hline GSE63089 & GPL5175 & China & 45 & 45 \\
\hline GSE13195 & GPL5175 & China & 25 & 25 \\
\hline GSE33335 & GPL5175 & China & 25 & 25 \\
\hline GSE56807 & GPL5175 & China & 5 & 5 \\
\hline GSE26899 & GPL6947 & USA & 96 & 12 \\
\hline GSE13861 & GPL6884 & USA & 65 & 19 \\
\hline GSE65801 & GPL14550 & China & 32 & 32 \\
\hline GSE103236 & GPL4133 & Romania & 10 & 9 \\
\hline GSE84787 & GPL17077 & China & 10 & 10 \\
\hline
\end{tabular}

GC, gastric cancer.

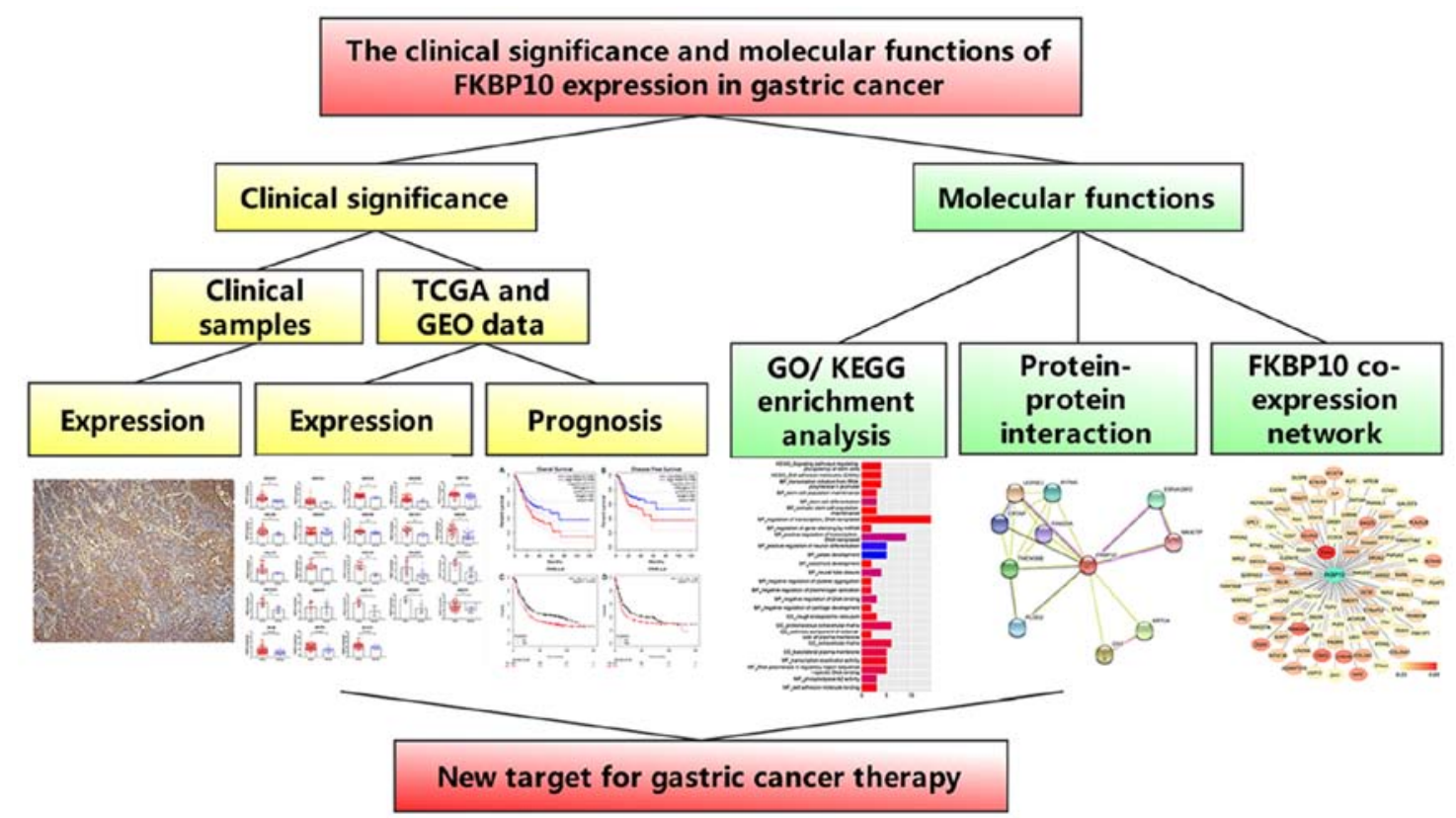

Figure 1. Flow chart of the study design of FKBP10 analysis in gastric cancer. FKBP10, FK506 binding protein 10.

in the regulation of GC development. FKBP10 co-expression networks were assessed using the GEPIA and Coexpedia online tools (http://www.coexpedia.org/) (31). Pearson correlation analysis of FKBP10 was conducted using GEPIA. Then, Gene Ontology (GO) and Kyoto Encyclopedia of Genes and Genomes (KEGG) pathway enrichment analyses were performed using the DAVID 6.8 (https://david.ncifcrf.gov/home.jsp).

\section{Results}

FKBP10 mRNA expression levels based on TCGA and GEO databases. A flow chart of our study design was presented in Fig. 1. FKBP10 is relatively expressed at high levels in a variety of tumors, except gynecological malignancies, including cervical squamous cell carcinoma, uterine corpus endometrial 
Table II. Association between gastric cancer and FKBP10 expression and clinicopathological features in The Cancer Genome Atlas.

\begin{tabular}{|c|c|c|c|c|}
\hline Clinicopathological parameters & Cases (n) & FKBP10 expression levels & $\mathrm{T}$ & P-value \\
\hline \multicolumn{5}{|l|}{ Age } \\
\hline$<60$ years & 122 & 10.612 & \multirow[t]{2}{*}{1.089} & \multirow[t]{2}{*}{0.277} \\
\hline$\geq 60$ years & 288 & 10.439 & & \\
\hline \multicolumn{5}{|l|}{ Sex } \\
\hline Male & 268 & 10.553 & \multirow[t]{2}{*}{1.216} & \multirow[t]{2}{*}{0.225} \\
\hline Female & 147 & 10.369 & & \\
\hline \multicolumn{5}{|l|}{ Stage } \\
\hline $\mathrm{I}+\mathrm{II}$ & 181 & 10.385 & \multirow[t]{2}{*}{-1.043} & \multirow[t]{2}{*}{0.298} \\
\hline $\mathrm{III}+\mathrm{IV}$ & 211 & 10.543 & & \\
\hline \multicolumn{5}{|l|}{ Grade } \\
\hline $\mathrm{G} 1+\mathrm{G} 2$ & 160 & 10.626 & \multirow[t]{2}{*}{1.519} & \multirow[t]{2}{*}{0.129} \\
\hline G3 & 255 & 10.400 & & \\
\hline \multicolumn{5}{|l|}{ T stage } \\
\hline $\mathrm{T} 1+\mathrm{T} 2$ & 110 & 10.499 & \multirow[t]{2}{*}{0.177} & \multirow[t]{2}{*}{0.860} \\
\hline $\mathrm{T} 3+\mathrm{T} 4$ & 296 & 10.469 & & \\
\hline \multicolumn{5}{|l|}{$\mathrm{N}$ stage } \\
\hline N1 & 123 & 10.251 & \multirow[t]{2}{*}{-1.862} & \multirow[t]{2}{*}{0.063} \\
\hline $\mathrm{N} 2+\mathrm{N} 3$ & 273 & 10.550 & & \\
\hline \multicolumn{5}{|l|}{ M stage } \\
\hline M0 & 367 & 10.460 & \multirow[t]{2}{*}{-1.113} & \multirow[t]{2}{*}{0.266} \\
\hline M1 & 27 & 10.786 & & \\
\hline \multicolumn{5}{|l|}{ Person neoplasm cancer status } \\
\hline Tumor free & 237 & 10.365 & \multirow[t]{2}{*}{-2.107} & \multirow[t]{2}{*}{$0.036^{\mathrm{a}}$} \\
\hline With tumor & 135 & 10.704 & & \\
\hline \multicolumn{5}{|l|}{ Recurrence } \\
\hline No & 313 & 10.416 & \multirow[t]{2}{*}{-1.728} & \multirow[t]{2}{*}{0.085} \\
\hline Yes & 102 & 10.706 & & \\
\hline
\end{tabular}

${ }^{\mathrm{a}} \mathrm{P}<0.05$. FKBP10, FK506 binding protein 10.

carcinoma and ovarian cancer (Fig. 2A). Additionally, FKBP10 was significantly overexpressed in GC tissues $\{n=408$, $\log _{2}[$ transcripts per million $\left.(\mathrm{TPM})+1]=5.06\right\}$ compared with in adjacent gastric tissues in the TCGA database $[n=36$, $\log 2(\mathrm{TPM}+1)=3.53 ; \mathrm{P}<0.001]$ (Fig. 2B). Expression levels in certain GC cell lines were consistent with those in GC tissues, each exhibiting medium expression levels (Fig. 2C). Among 19 GEO microarray analyses, FKBP10 expression levels in GC tissues were significantly increased than in adjacent tissues (GSE29272, GSE54129, GSE26899, GSE27342, GSE13861, GSE63089, GSE13911, GSE65801, GSE13195, GSE33335, GSE89148, GSE19826, GSE79973, GSE103236, GSE51725, GSE56807 and GSE2701) (Fig. 3). After batch effects removal of platform GPL96, GPL570 and GPL5175, FKBP10 also exhibited significantly increased expression in the combined GC samples compared with in normal samples (Fig. 3). Furthermore, a comprehensive meta-analysis indicated that FKBP10 expression in GC tissues was upregulated than in adjacent tissues $[\mathrm{SMD}=1.31,95 \%$ confidence interval $(\mathrm{CI})$ : 1.02-1.6; $\mathrm{P}<0.001]$ (Fig. 4A). Additionally, forest plots of removal batch effects showed a consistent expression trend in GC tissues (SMD=1.09, 95\% CI: 0.81-1.37, P<0.001) (Fig. 4B). No significant publication bias was determined in either funnel plot $(\mathrm{P}=0.125$ and $\mathrm{P}=0.124)$ (data not shown). The association between the differential expression of FKBP10 and the clinicopathological features of patients with GC was investigated. As for cancer status, FKBP10 expression in patients with GC was significantly higher than in tumor-free patients, but there were no significant differences between FKBP10 expression and stage, grade, $\mathrm{T}$ stage, $\mathrm{N}$ stage and $\mathrm{M}$ stage (Table II). FKBP10 expression was significantly associated with the clinicopathological factor of person neoplasm cancer status. This indicated that tumor status could be closely related to FKBP10 expression; however, FKBP10 was not significantly linked to other clinical parameters. This may be due an insufficient sample size. Histological types were classified as gastrointestinal adenocarcinoma (tubular, papillary, not otherwise specified and mucinous type) and stomach adenocarcinoma (not otherwise specified, diffuse and signet ring type). Unfortunately, FKBP10 expression did not significantly 
A

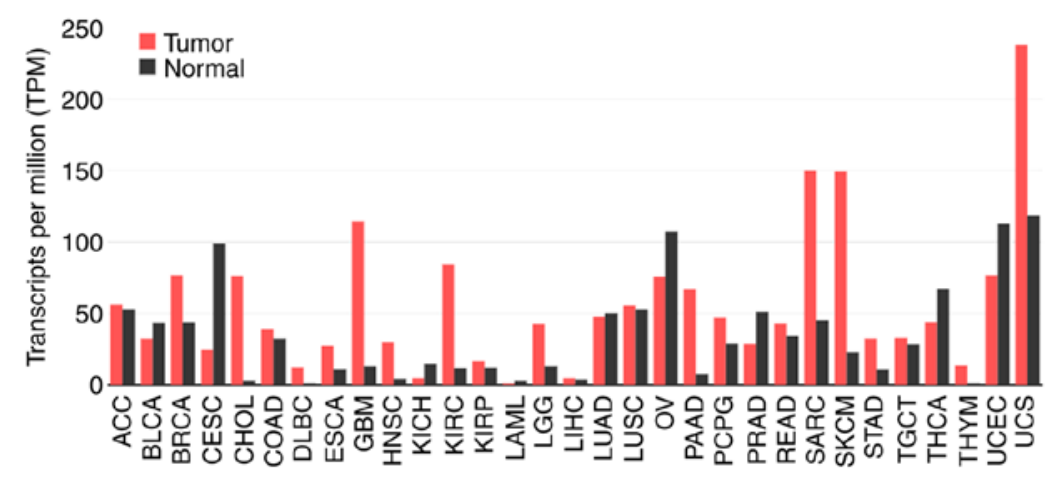

C

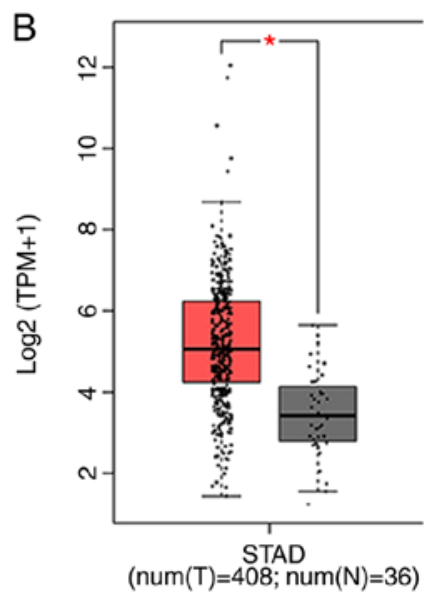

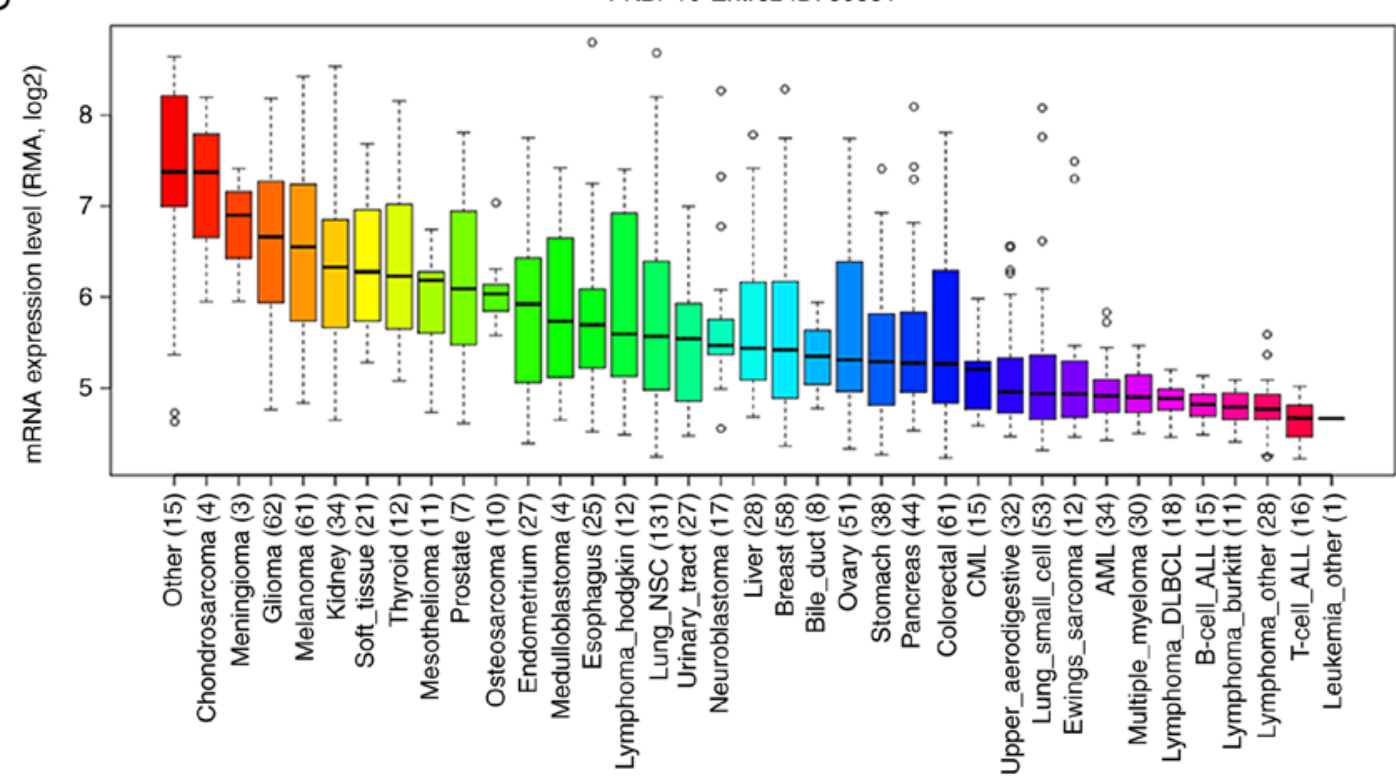

Figure 2. FKBP10 mRNA expression levels. (A) Histogram of FKBP10 expression in various types of cancer. (B) FKBP10 expression in gastric cancer tissues $\left[\log _{2}(\mathrm{TPM}+1)=5.06\right]$ was significantly higher than in normal tissues $\left[\log _{2}(\mathrm{TPM}+1)=3.53\right],\left({ }^{*} \mathrm{P}<0.001\right)$. (C) Histogram of FKBP10 expression levels in gastric cancer cells, which were the median between those of several cancer cell lines. The histogram was downloaded from The Cancer Cell Line Encyclopedia. Different colors represented the expression level of FKBP10 in different cell types. FKBP10, FK506 binding protein 10; SATD, stomach adenocarcinoma; TPM, transcripts per million.

differ between gastric and gastrointestinal adenocarcinoma. In addition, there was no significant relationship between FKBP10 expression and differentiated adenocarcinoma. The receiver operating characteristic (ROC) curve for FKBP10 based on GEO was presented in Fig. 5. The area under the curve was 0.774-1 $(\mathrm{P}=0.001)$. The ROC curve of FKBP10 was 0.773 in TCGA $(\mathrm{P}<0.001$; Fig. 5). The combined microarray data had a sensitivity of 0.77 (0.64-0.86), a specificity of 0.89 (0.83-0.93), and an area under the combined SROC curve of 0.91 (0.89-0.94) (Fig. 6). No significant publication bias was observed $(\mathrm{P}=0.04)$. The frequency of FKBP10 alterations in TCGA was 9\% (35/393), with 24 amplifications, 6 missense mutations and 5 truncating mutations, with no alterations in the remaining sections (Fig. 7A). Subsequently, DNA methylation analysis revealed the methylation level across FKBP10 gene regions [promoter, enhancer, TSS1500, TSS200, 5'untranslated region (UTR), first exon, gene body and 3'UTR), as well as CpG islands/CPG island regions, shelves and shores (Fig. 7B).
Prognostic value of FKBP10.FKBP10 has potential for predicting the prognosis of patients with GC. Patients with high FKBP10 expression had a significantly shorter OS time relative to patients with low expression FKBP10 (hazard ratio $(\mathrm{HR})=1.5 ; \mathrm{P}=0.014$ ) (Fig. 8A). In addition, patients with high expression of FKBP10 had shorter durations of DFS than those with low expression (HR=1.6, $\mathrm{P}=0.021$; Fig. 8B). We also verified in the GEO database that patients with high expression of FKBP10 had significantly shorter OS and DFS times than patients with low expression $(\mathrm{HR}=1.36, \mathrm{P}<0.001 ; \mathrm{HR}=1.27, \mathrm{P}=0.017$ ) (Fig. $8 \mathrm{C}$ and $\mathrm{D})$. Using univariate cox analysis, we found that FKBP10 expression levels, age, tumor, node and metastasis (TNM) stage, grade, T stage and $\mathrm{N}$ stage were closely associated with prognosis. Subsequently, multivariate analysis indicated that FKBP10 expression, age and TNM staging could be independent prognostic factors for patients with GC (Table III).

FKBP10 protein expression in GC. We downloaded FKBP10 protein expression data pertaining to GC from the HPA. We 

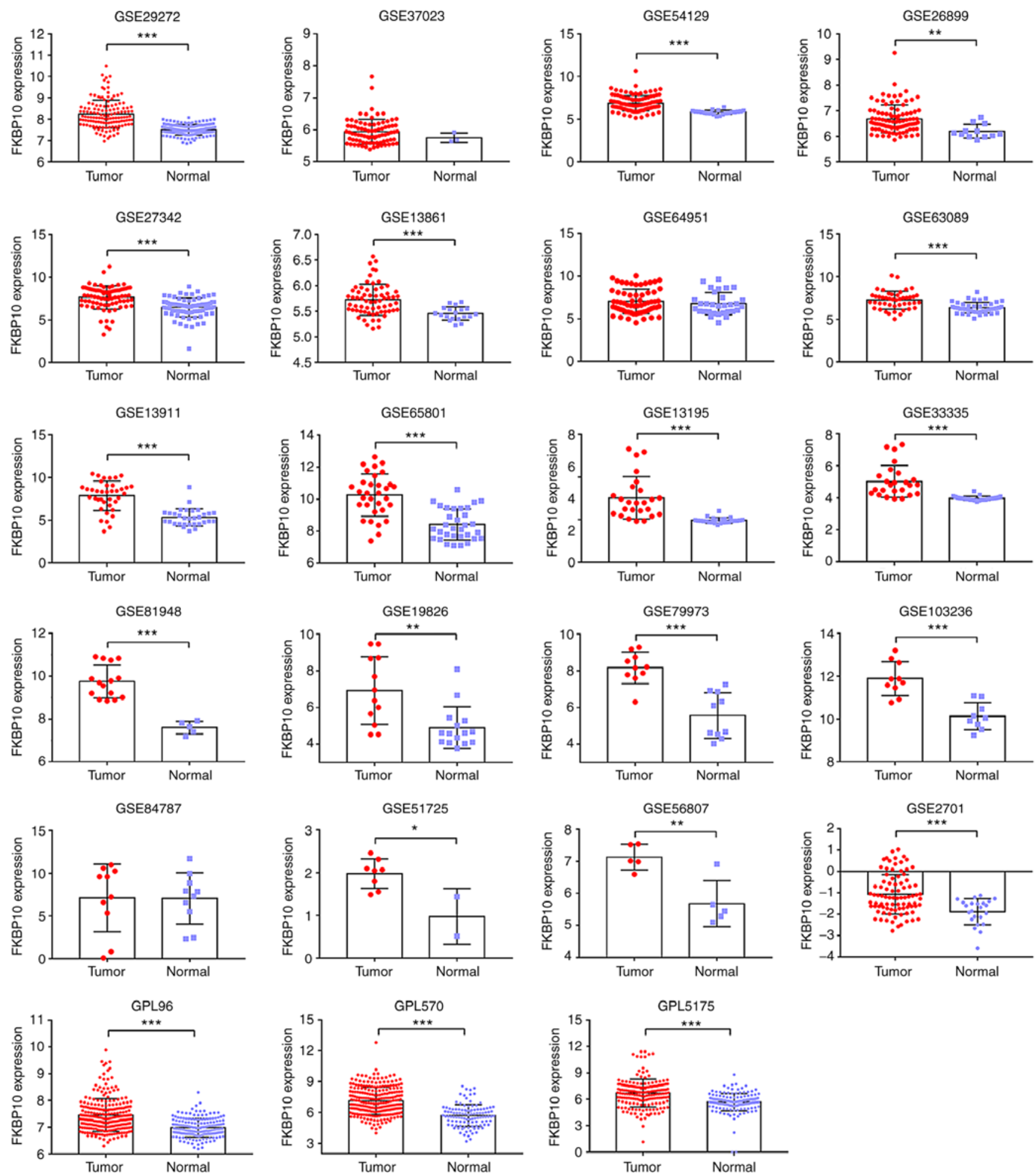

Figure 3.FKBP10 expression based on Gene Expression Omnibus microarray data. FKBP10 expression was assessed by microarray analysis. A total of 17 series (GSE29272, GSE54129, GSE26899, GSE27342, GSE13861, GSE63089, GSE13911, GSE65801, GSE13195, GSE33335, GSE89148, GSE19826, GSE79973, GSE103236, GSE51725, GSE56807, GSE4701) revealed FKBP10 to be significantly overexpressed in gastric cancer relative to that in normal tissues. The same platform microarrays underwent batch effects removal and then processed into our workflow. GPL96 contained GSE29272 and GSE37023, GPL570 contained GSE54129, GSE64951, GSE13911, GSE19826, GSE79973 and GSE51725, while GPL5175 had GSE27342, GSE63089, GSE13195, GSE33335 and GSE56807. ${ }^{*} \mathrm{P}<0.05 ;{ }^{* * *} \mathrm{P}<0.01 ;{ }^{* * *} \mathrm{P}<0.001$. A paired t-test was used to analyze the data of paired samples, while unpaired t-test was used to analyze unpaired samples. FKBP10, FK506 binding protein 10.

reported that 4/10 GC tissue samples exhibited positive staining with HPA057021 antibody (Fig. 9A). Compared with cancer tissues, upregulated FKBP10 protein expression was not detected in normal tissues (Fig. 9B). In addition, we validated 40 pairs of
GC tissues and corresponding adjacent tissues by immunohistochemistry and calculated the IRS scores. The expression of FKBP10 in GC tissues (IRS=5.6) was significantly increased than in adjacent tissues (IRS=0.002, P $<0.001$; Fig. 9C and D). 
A

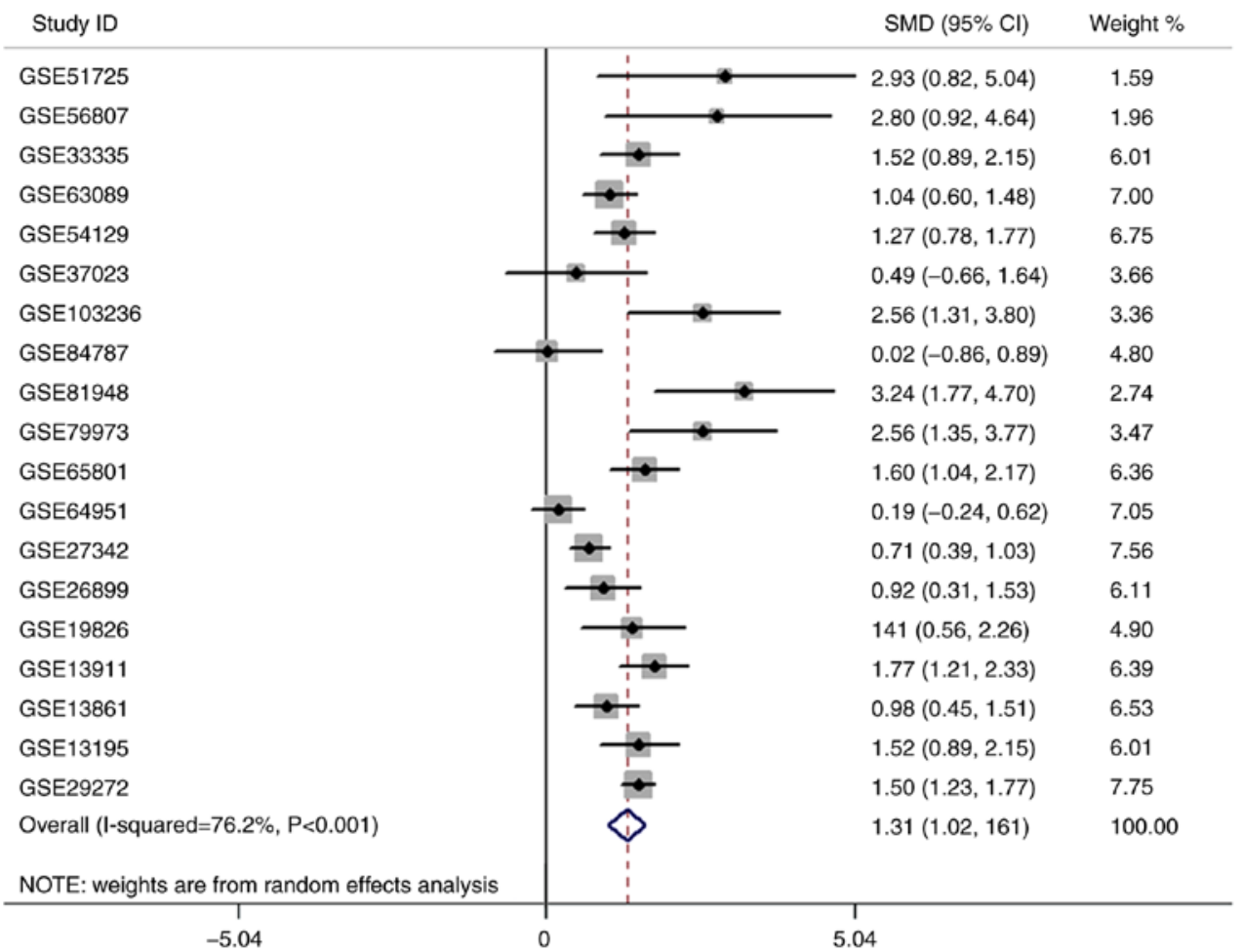

B

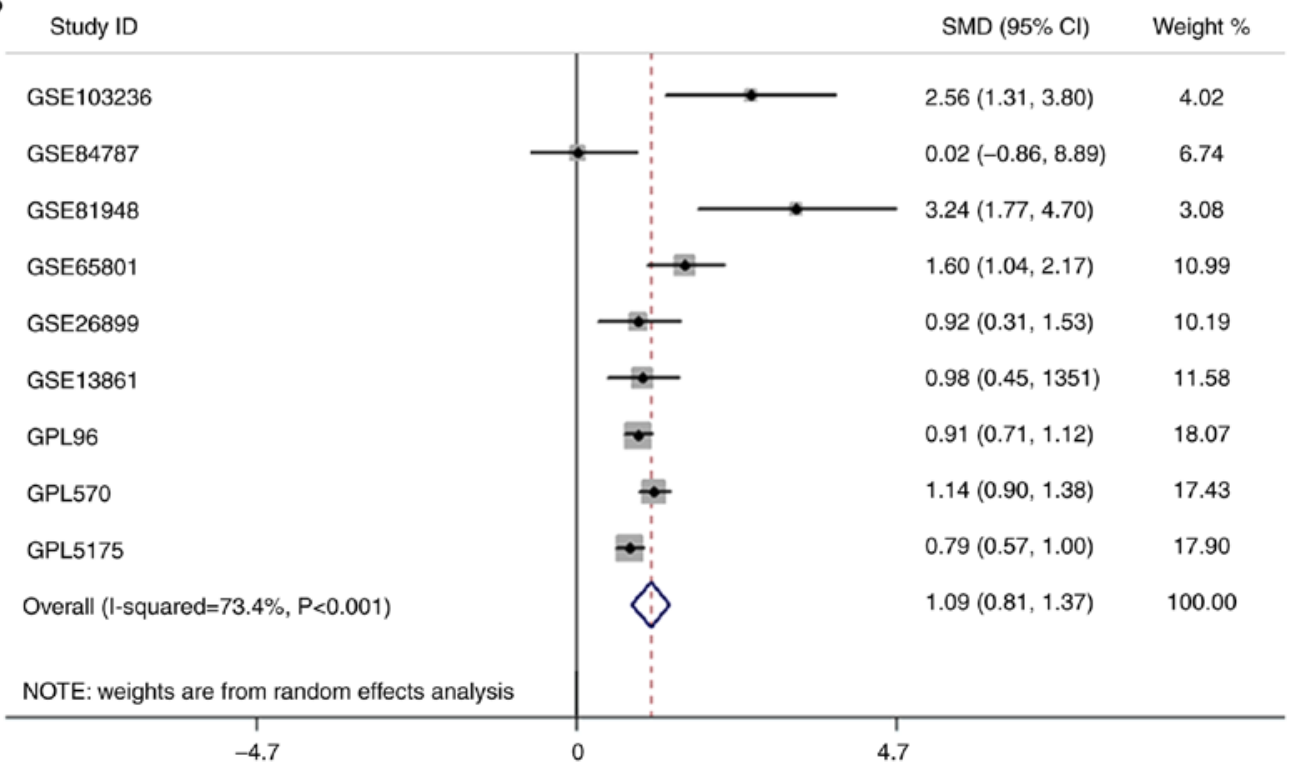

Figure 4. Forest plot of FKBP10 expression. (A) Expression of FKBP10 was significantly overexpressed in GC tissues relative to non-GC tissues (SMD=1.31, 95\% CI, 1.02-1.61). (B) Removal of batch effects of the same platform series (GPL96, GPL570 and GPL5175). FKBP10 expression was consistently overexpressed in GC relative to non-GC tissues (SMD=1.09, 95\% CI, 0.81-1.37). CI, confidence interval; FKBP10, FK506 binding protein 10; GC, gastric cancer; SMD, standardized mean difference.

Biological function analysis. To explore the biological function of FKBP10, we identified and analyzed the proteins that interact with FKBP10 via PPI analysis. We found that dystonin, leucine- and proline-enriched proteoglycan 1 (also known as $\mathrm{P} 3 \mathrm{H} 1$ ), keratin 14 and transmembrane protein 38B could interact with FKBP10 (genes combined score $>0.7$ ) (Fig. 10). We also searched for genes closely related to FKBP10 expression; a FKBP10 co-expression network of TCGA and GEO data was created and analyzed by GEPIA and Coexpedia, respectively (Fig. 11). Additionally, prolyl 3-hydroxylase family member 4 (P3H4, also known as LEPREL4) was identified as the most closely related gene in from TCGA and GEO network analyses $(\mathrm{R}=0.89, \mathrm{P}<0.001$; Fig. 12). We also ran GO and KEGG pathway analyses of co-expressed genes. The results of KEGG enrichment showed that the most significantly enriched pathways were regulating the 'pluripotency of stem cells', 'cell adhesion molecules', 'vasopressin-regulated water reabsorption', 'ras signaling', 'lysine degradation', 'insulin signaling', 'glutathione metabolism', 'glucagon signaling' and ‘estrogen signaling pathway’ (Fig. 13). 

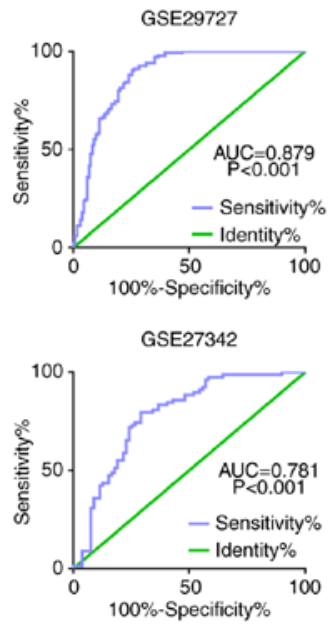

GSE13911

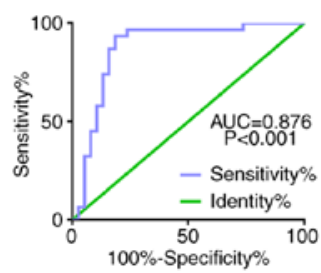

GSE81948

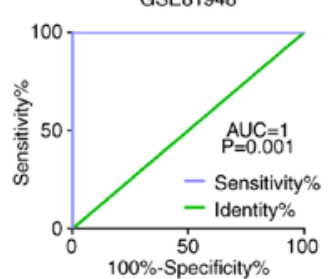

GSE84787

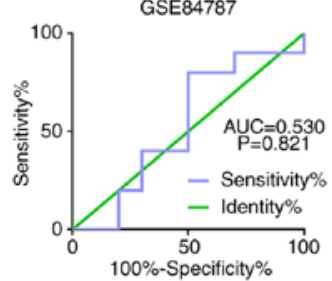

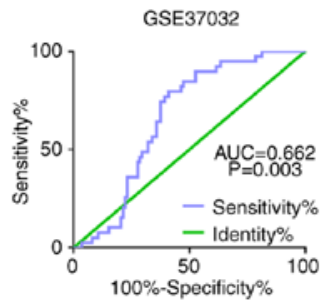
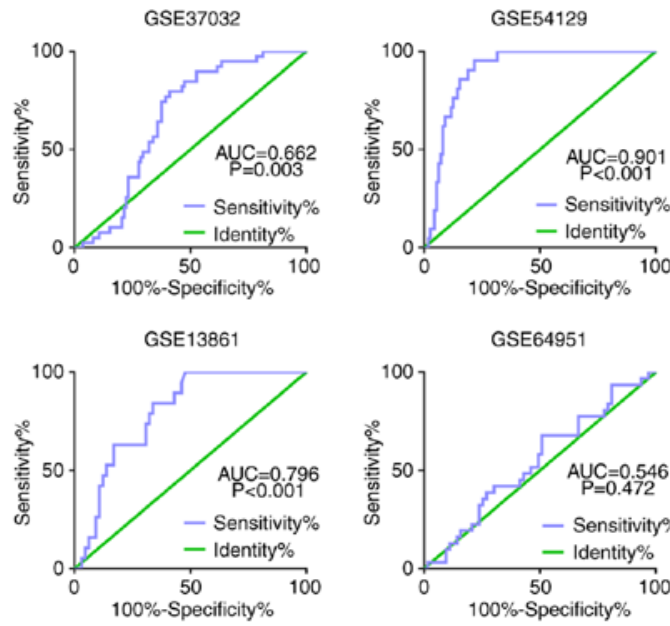

GSE6495
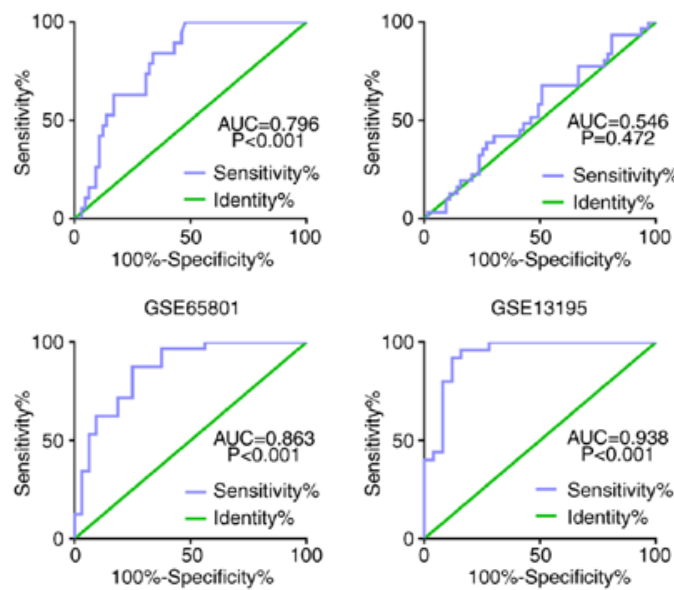

GSE19826
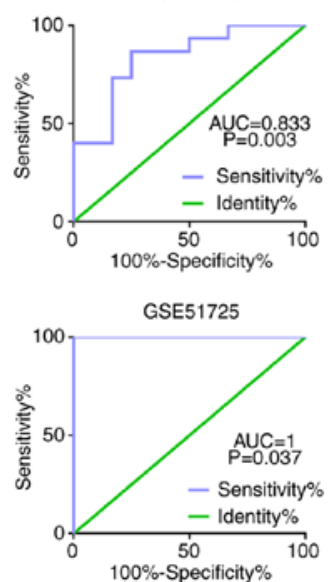

GSE13195

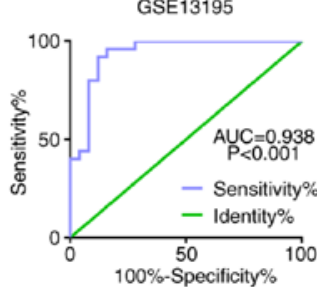

GSE79973
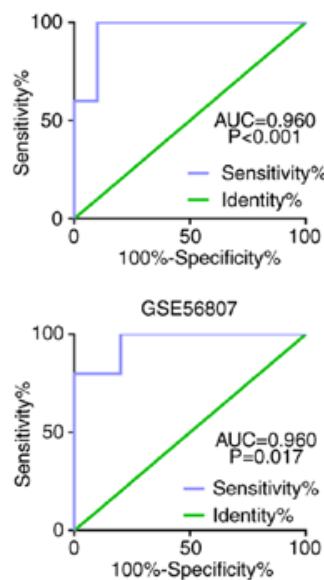

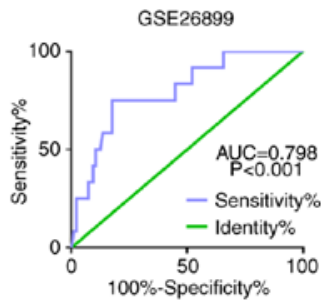

GSE63089

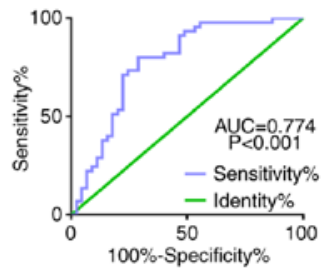

GSE33335

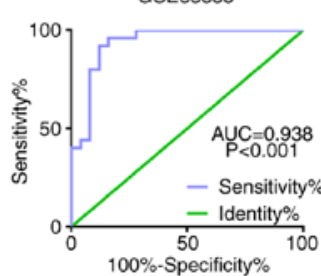

GSE103236
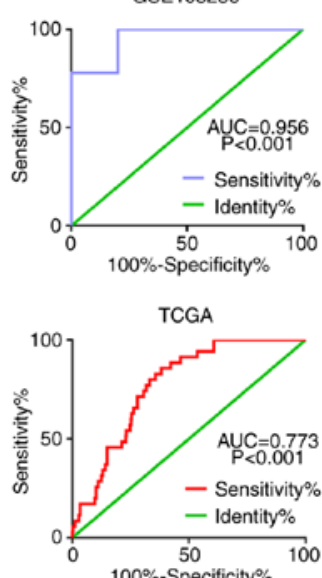

Figure 5. FK506 binding protein 10 receiver operating characteristic curve in the GEO and TCGA. Among GEO data, 17 series and TCGA data showed significant diagnostic potential $(\mathrm{P}<0.05)$. AUC, area under the curve; GEO, Gene Expression Omnibus; TCGA, The Cancer Genome Atlas.

\section{Discussion}

To the best of our knowledge, the present study is the first to comprehensively investigate the characterization of FKBP10 in GC. We initially found that FKBP10 is highly expressed in GC using the GEO and TCGA databases. Subsequently, we verified that the protein expression levels of FKBP10 were consistent with the data of GEO and TCGA by immunohistochemistry. In addition, the expression of FKBP10 was determined to be closely associated with clinical prognosis. It was found in the TCGA and GEO datasets that patients with GC and high expression of FKBP10 had lower DFS and OS times than those with low expression. In addition, multivariate $\mathrm{COX}$ analysis demonstrated that FKBP10 was an independent prognostic factor for GC. Collectively, the results of the present study suggests that FKBP10 may be a key target gene involved in the development of GC.

As an endoplasmic reticulum localization protein, FKBP65 binds to tropoelastin throughout the secretory process (32).

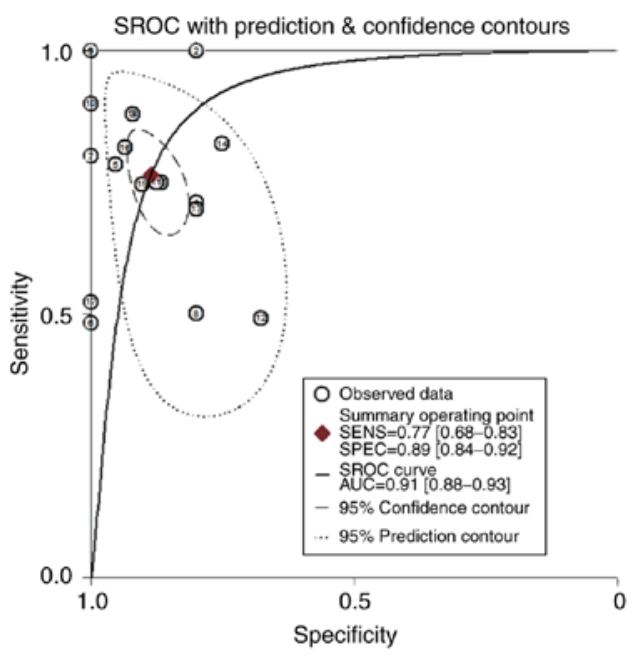

Figure 6. SROC curve of FK506 binding protein 10. AUC of SROC curve is 0.91 (95\% CI, 0.88-0.92). SROC, summary receiver operating characteristic. 
Table III. Cox regression model analysis of overall survival in patients with gastric cancer.

\begin{tabular}{|c|c|c|c|c|c|c|}
\hline \multirow[b]{2}{*}{ Covariates } & \multicolumn{3}{|c|}{ Univariate analysis } & \multicolumn{3}{|c|}{ Multivariate analysis } \\
\hline & HR & $95 \%$ confidence interval & P-value & HR & $95 \% \mathrm{CI}$ & P-value \\
\hline FKBP10 expression level & 1.192 & $1.076-1.319$ & $0.001^{\mathrm{a}}$ & 1.159 & $1.042-1.289$ & $0.006^{\mathrm{a}}$ \\
\hline Age ( $<60$ vs. $\geq 60$ years) & 1.482 & $1.028-2.136$ & 0.035 & 1.627 & $1.117-2.370$ & 0.011 \\
\hline Sex (male vs. female) & 0.772 & $0.546-1.091$ & 0.143 & & & \\
\hline T stage (T1-2 vs. T3-4) & 1.799 & $1.195-2.708$ & $0.005^{\mathrm{a}}$ & & & \\
\hline $\mathrm{N}$ stage (N0 vs. N1-3) & 2.096 & $1.389-3.164$ & $<0.001^{\mathrm{a}}$ & 2.059 & $1.357-3.122$ & $0.001^{\mathrm{a}}$ \\
\hline M stage (M0 vs. M1) & 1.137 & $0.614-2.103$ & 0.683 & & & \\
\hline Histological grade (G1-2 vs. G3) & 1.398 & $0.997-1.961$ & 0.052 & & & \\
\hline
\end{tabular}

${ }^{\mathrm{a}} \mathrm{P}<0.05$. FKBP10, FK506 binding protein 10.

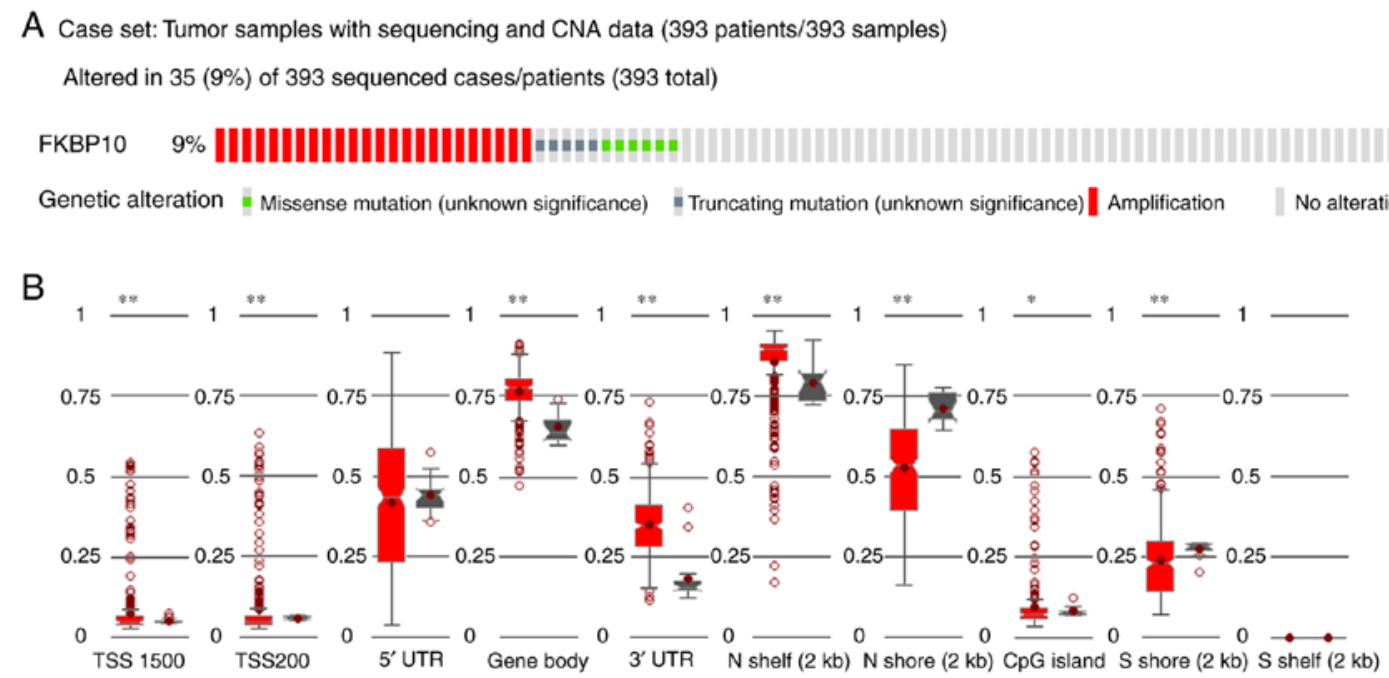

Figure 7. Genetic alterations and methylation of FKBP10. (A) FKBP10 was revealed to have more genetic alterations in The Cancer Genome Atlas cohort. A total of 24 cases had FKBP10 amplifications, 5 had truncating mutations and 6 possessed missense mutations. (B) The methylation levels of FKBP10 across gene regions (TSS1500, TSS200, 5'UTR, gene body, 3'UTR) and CpG islands, as well as shelves and shores in gastric cancer. ${ }^{*} \mathrm{P}<0.05$, ${ }^{* *} \mathrm{P}<0.005$. CNA, copy number alteration; FKBP10, FK506 binding protein 10; UTR, untranslated region.

Investigations into FKBP10 have primarily focused on pulmonary fibrosis and osteochondrosis; FKBP10 mutations has been linked to the onset of many diseases $(33,34)$. As a connective tissue disease, Bruck syndrome is mainly characterized by the loss of endopeptide lysine hydroxylation at the molecular level, leading to the reduction of collagen pyrimidine cross-linking (35). The literature indicates that FKBP65 crosslinks with pyridine by mediating the dimerization of LH2 (35-37). FKBP10 expression was determined to be upregulated in idiopathic pulmonary fibrosis and bleomycin-induced lung fibrosis (12). Importantly, the loss of FKBP10 expression significantly suppressed collagen secretion by primary human lung fibroblasts (12). Downregulated expression of FKBP10 leads to decreased collagen type I a 1chain mRNA levels, resulting in liver fibrosis and collagen accumulation (38).

In recent years, the relationship between FKBP10 and cancer has been investigated. The main function of FKBP10 is to control folding, trafficking and secretion of protein during the production of extracellular matrix proteins (32).
FKBP10 is highly expressed in melanoma and colorectal cancer $(22,39)$. Downregulated FKBP10 can suppress tumor growth in KRAS-driven lung tumors (18). Decreasing the expression of FKBP10 can inhibit the proliferation and migration of renal cancer cells, affecting the cell cycle (21). The transcription factor ETS variant 1 targets FKBP10 to regulate the invasion and migration of prostate cancer cells $(19,40)$. However, in ovarian cancer $(16,17)$, the expression profile of FKBP10 opposed that to other tumors; the mechanism of action by which FKBP10 may be involved differs, yet further investigation is required. In addition, the expression and function of FKBP10 has not yet been reported in GC.

According to GO analysis, FKBP10 significantly correlated with protein and collagen production. KEGG pathway enrichment analysis showed that FKBP10 may be related to cell migration, particularly via cell adhesion molecules and ECM-receptor interaction pathways. These results are similar to those of Romano et al (32). FKBP10 protein localizes to the endoplasmic reticulum (ER) and acts as a molecular 
A
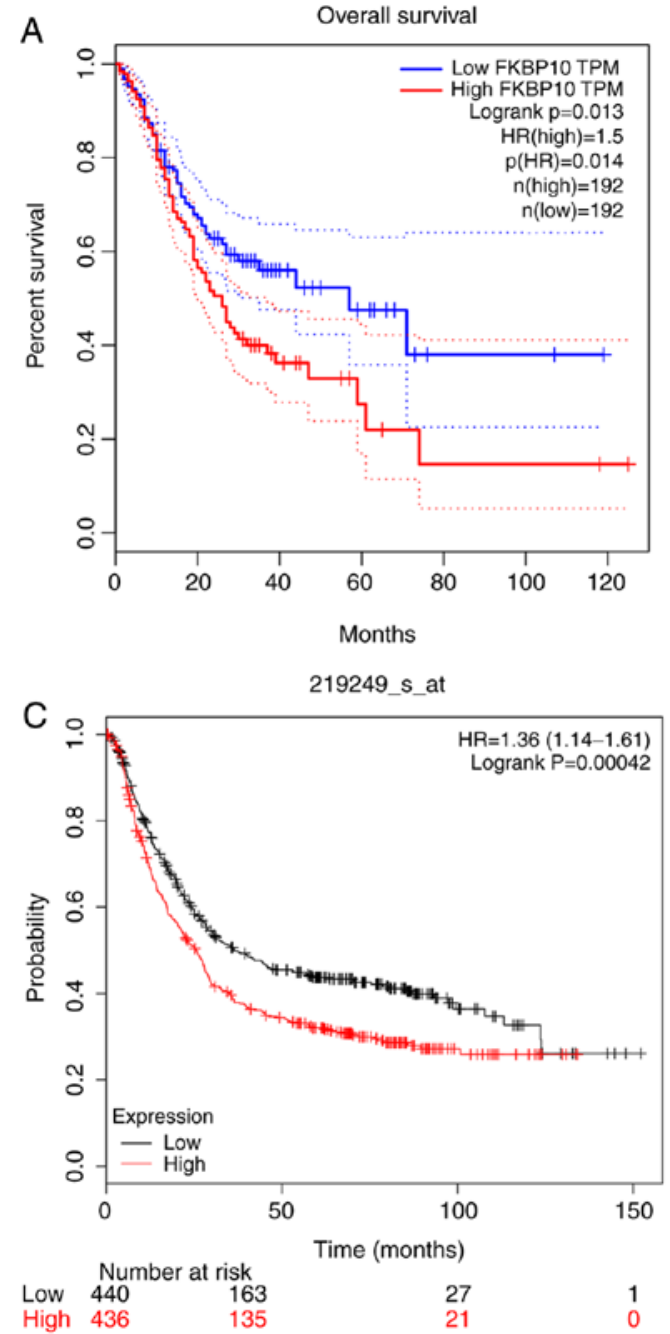

B

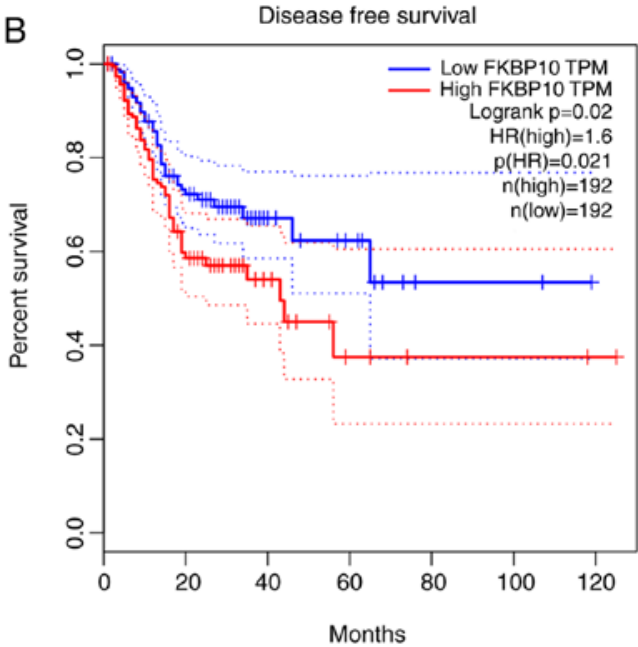

$219249 \mathrm{~s}$ at

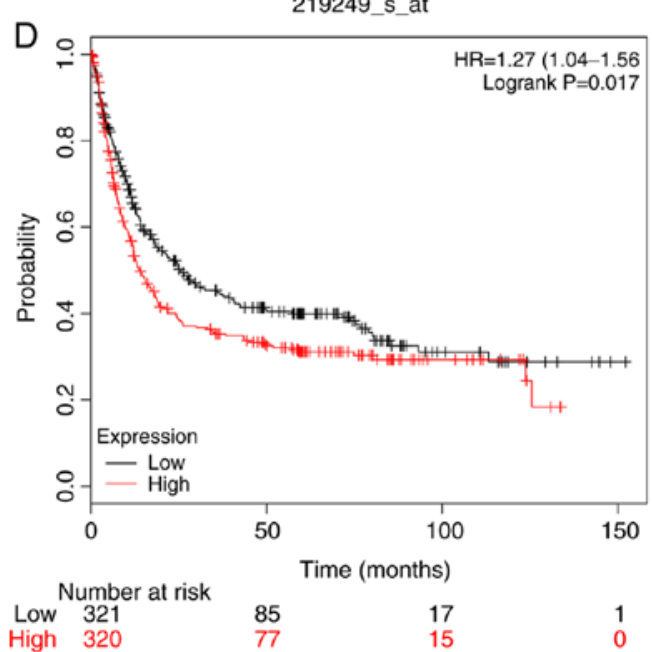

Figure 8. Kaplan-Meier analysis of FKBP10, and OS and DFS of gastric cancer. (A) OS time of the low FKBP10-expression group was longer than of the high expression group based on TCGA data $(\mathrm{P}=0.013)$. (B) DFS time of the low FKBP10-expression group in low group was longer than that of the high expression group based on TCGA data $(\mathrm{P}=0.02)$. (C) OS time of the low FKBP10-expression group was longer than that of the high expression group based on GEO data $(\mathrm{P}<0.001)$. (D) DFS time of the low FKBP10-expression group was longer than that of the high-expression group based on TCGA data ( $\mathrm{P}=0.017)$. Plots were created using a Gene Expression Profiling Interactive Analysis and Kaplan-Meier Plotter tools. DFS, disease-free survival; FKBP10, FK506 binding protein 10; GEO, Gene Expression Omnibus; HR, hazard ratio; OS, overall survival; TCGA, The Cancer Genome Atlas; TPM, transcripts per million.
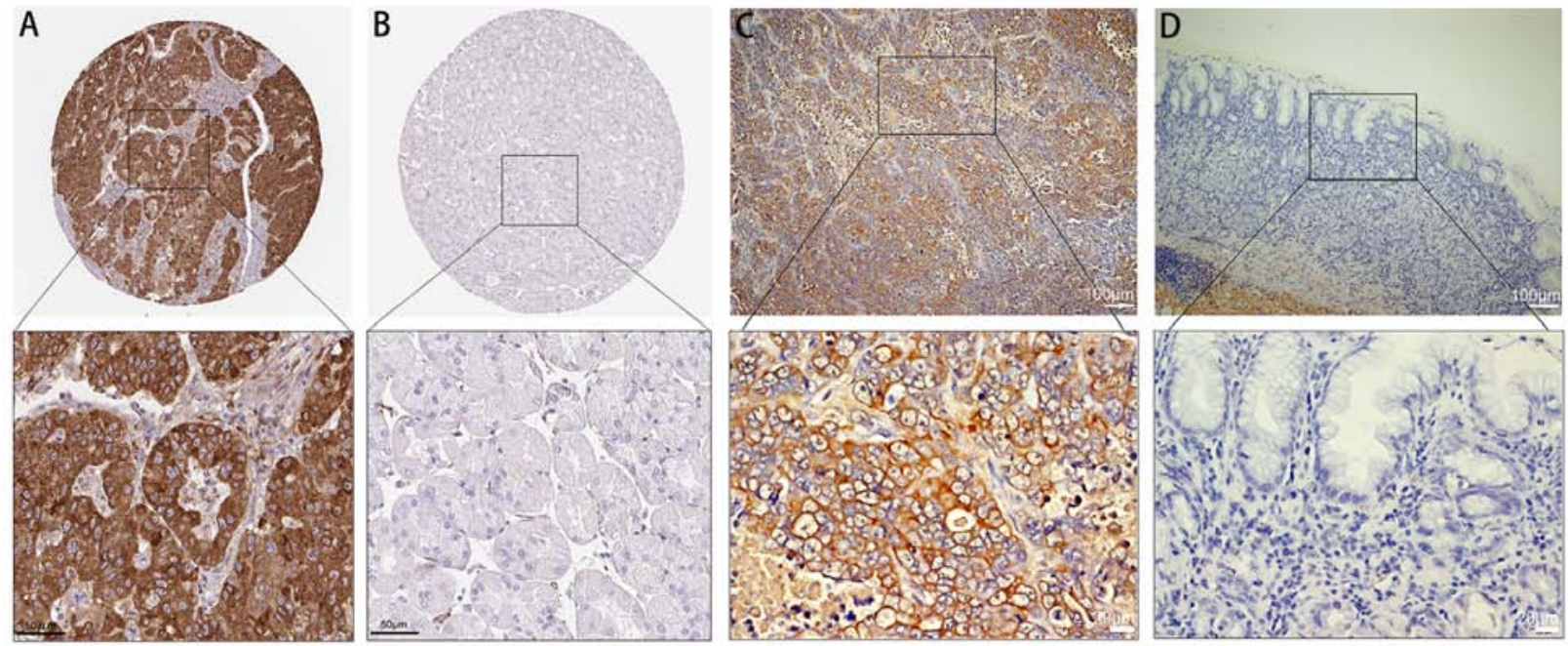

Figure 9. Immunohistochemistry analysis of FKBP10. (A) Immunostaining of FKBP10 in gastric cancer tissue from the HPA. High cytoplasmic staining for FKBP10. (B) Immunostaining of FKBP10 in paired normal gastric tissues from the HPA; no detectable staining of FKBP10 was observed. (C and D) FKBP10 expression levels in the gastric cancer group $(\mathrm{n}=40, \mathrm{IRS}=5.6)$ were notably higher than the paired adjacent normal tissues $(\mathrm{IRS}=0.002, \mathrm{P}<0.001)$. Magnification, x200. A paired t-test was used for analysis. FKBP10, FK506 binding protein 10; HPA, Human Protein Atlas; IRS, immunoreaction score. 


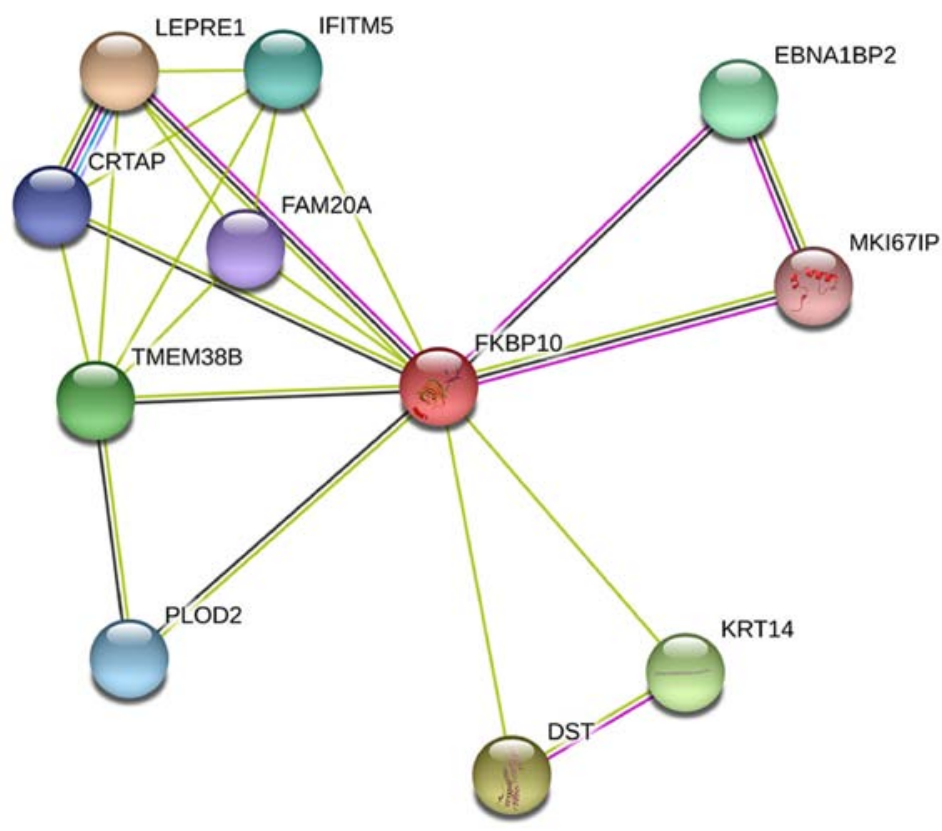

Figure 10. Protein-protein interaction analysis of FKBP10. FKBP10 is likely to associate with DST, CRTAP (P3H5), LEPRE1 (P3H1), KRT14 and TMEM38B An interaction score of 0.4 was set as cut-off value. DST, dystonin; CRTAP, cartilage associated protein; EBNA1BP2, EBNA1 binding protein 2; FAM20A, family with sequence similarity 20, member A; FKBP10, FK506 binding protein 10; IFITM5, interferon-induced transmembrane protein 5; LEPRE1, leprecan; KRT14, keratin 14; PLOD2, procollagen-lysine, 2-oxoglutarate 5-dioxygenase 2; TMEM38B, transmembrane protein 38B.
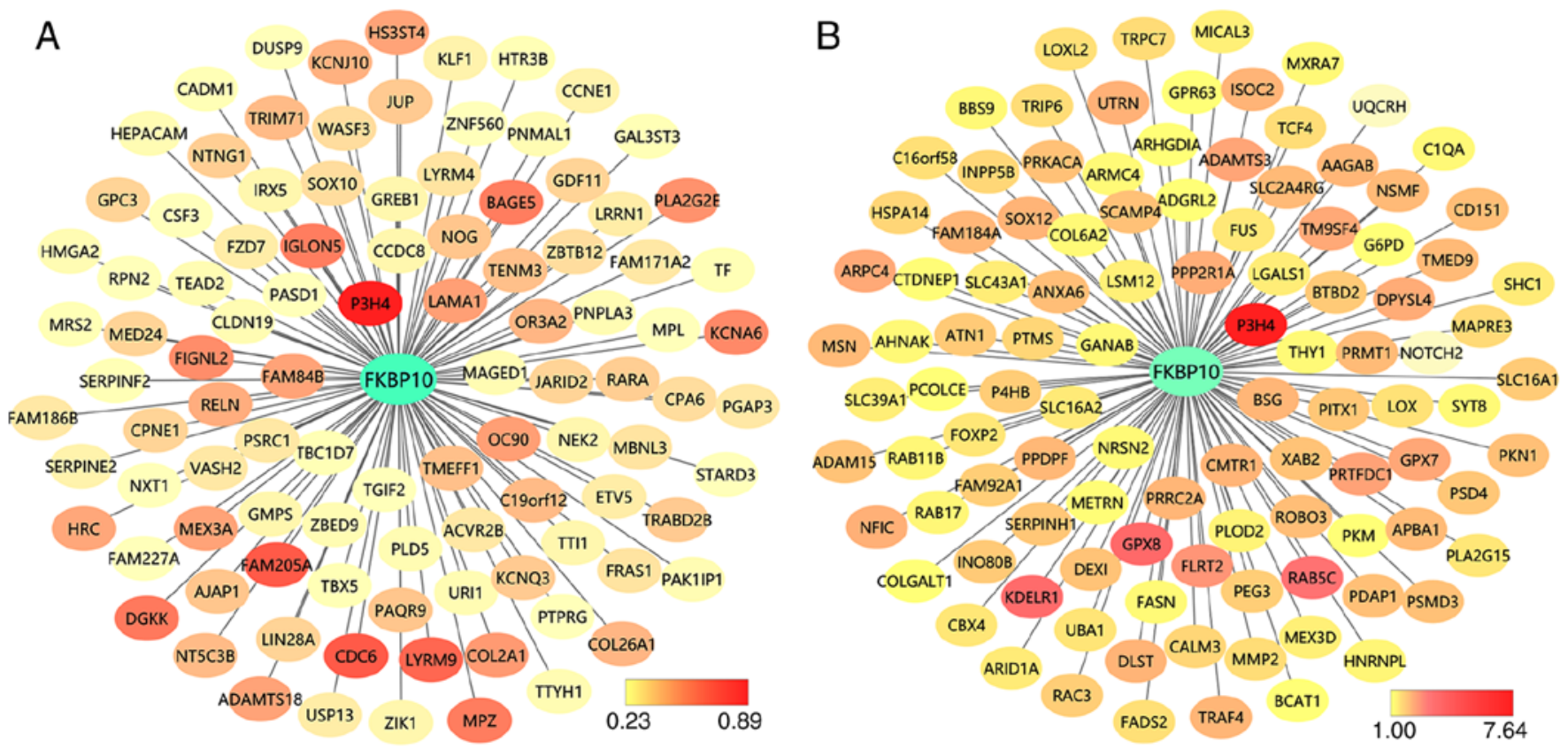

Figure 11. FKBP10 co-expression gene networks in gastric cancer. (A) Genes co-expressed with FKBP10 were ranked via Pearson's correlation coefficient with The Cancer Genome Atlas data in Gene Expression Profiling Interactive Analysis. (B) FKBP10 co-expression network was inferred from an individual series dataset of Gene Expression Omnibus in Coexpedia. Yellow indicated a lower degree of association with FKBP10, while red indicated a higher degree of association with FKBP10. FKBP10, FK506 binding protein 10.

chaperone (18). We reported that $\mathrm{P} 3 \mathrm{H} 4$ was the most commonly expressed gene with FKBP10. The data indicated that $\mathrm{P} 3 \mathrm{H} 4$ acts as part of an ER complex with prolyl 3-hydroxylase 3, which affects collagen lysine hydroxylation (41). This suggests that FKBP10 may interact with proline 3-hydroxylase to affect collagen synthesis. Although our study found that the expression of FKBP10 could be related to the prognosis of patients with GC, how FKBP10 regulates the progression of GC and how this can be applied for the targeted treatment of GC requires further investigation.

Of note, there were limitations to the present study. First, survival analysis was conducted using GEPIA and Kaplan Meier Plotter tools. The survival time of DFS should be shorter than OS. However, the result of our analysis showed 

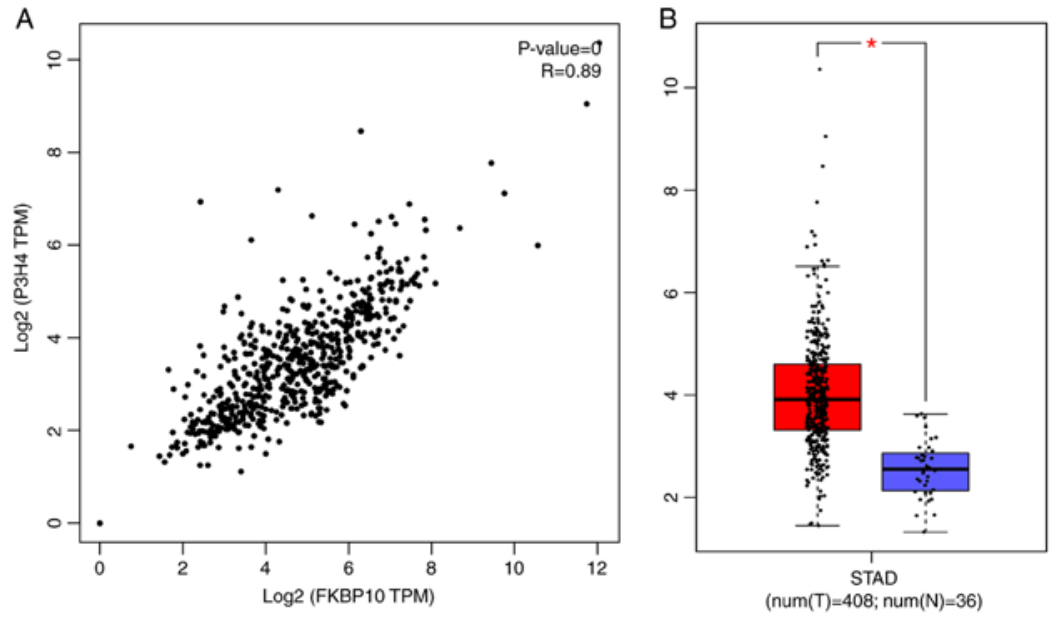

Figure 12. Co-expression of $\mathrm{P} 3 \mathrm{H} 4$ with FKBP10 in gastric cancer tissues. (A) FKBP10 was significant positive correlation to $\mathrm{P} 3 \mathrm{H} 4$ ( $\mathrm{R}=0.89$, $\mathrm{P}<0.001)$. $\mathrm{P} 3 \mathrm{H} 4$ may be the most likely to interact with FKBP10. (B) P3H4 was significantly overexpressed in gastric cancer tissues $\left[\mathrm{n}=408, \log _{2}(\mathrm{TPM}+1)=3.91\right]$ compared with in normal gastric tissues $\left[\mathrm{n}=36, \log _{2}(\mathrm{TPM}+1)=2.38,{ }^{*} \mathrm{P}<0.05\right]$. FKBP10, FK506 binding protein 10; $\mathrm{P} 3 \mathrm{H} 4$, prolyl 3-hydroxylase family member 4 .

A

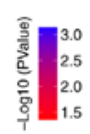

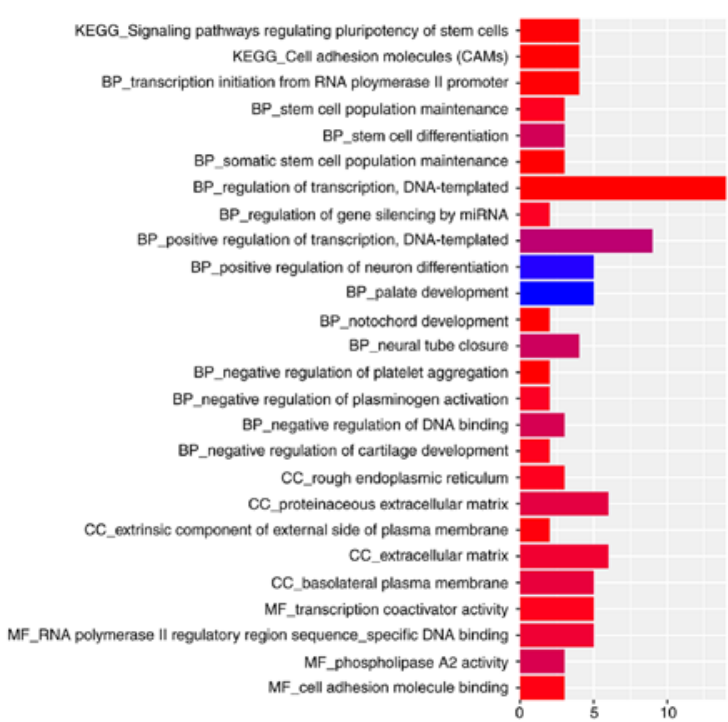

B

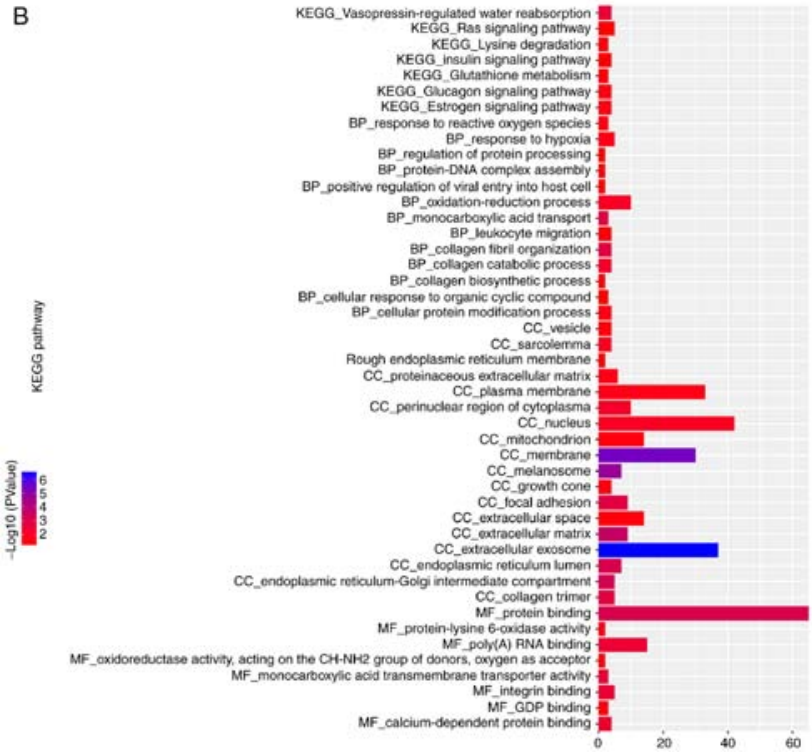

Figure 13. KEGG and Gene Ontology analysis of co-expression genes associated with FKBP10. (A) Co-expression genes were derived from Gene Expression Profiling Interactive Analysis and The Cancer Genome Atlas data. (B) Co-expression genes were derived from the Coexpedia of Gene Expression Omnibus series dataset. The horizontal axis represents the gene count for each functional term. Colors represent the P-value of function enrichment analysis. Blue indicated higher degrees of significance of gene enrichment analysis than red. BP, biological process; CC, cellular component; KEGG, Kyoto Encyclopedia of Genes and Genomes; MF, molecular function.

the reverse. Among the TCGA and GEO data, some patients are still being followed up, so the data are incomplete and still required further sample verification. We aim to verify the relationship between FKBP10 and patient prognosis using our own samples in the future. At the protein level, we only verified this relationship using immunohistochemistry; however, further validation using PCR and western blotting will be conducted in the future. In addition, the biological role of FKBP10 in gastric cancer cells should be investigated. Regarding the biological mechanism of FKBP10 in cancer, we have only proposed some options, yet the oncogenic function of FKBP10 should be further confirmed by in vitro and in vivo experiments.

In summary, the present study reported that FKBP10 is significantly elevated in GC; thus; FKBP10 could be considered as a potential novel therapeutic target for the treatment of this disease.

\section{Acknowledgements}

Not applicable.

\section{Funding}

The present study was supported by the Key Research and Development Program of Science and Technology Department of Guangxi (grant no. 2017AA45153), the Scientific Research and Technology-development Program of Guangxi (grant no. 1598011-4) and Innovation Project of Guangxi Graduate Education (grant no. YCBZ2019043). 


\section{Availability of data and materials}

The datasets used during the present study are available from the corresponding author upon reasonable request.

\section{Authors' contributions}

JQC and GC designed and directed the project. LL and $\mathrm{KZ}$ processed and analyzed data; LL wrote and revised the manuscript. XGQ and JHZ performed the immunohistochemistry experiment. All authors read and approved the manuscript and agree to be accountable for all aspects of the research in ensuring that the accuracy or integrity of any part of the work are appropriately investigated and resolved.

\section{Ethics approval and consent to participate}

The present study was approved by the Ethics Committee of The First Affiliated Hospital of Guangxi Medical University and all patients provided written informed consent.

\section{Patient consent for publication}

Not applicable.

\section{Competing interests}

The authors declare that they have no competing interests.

\section{References}

1. Correa P: Gastric cancer: Overview. Gastroenterol Clin North Am 42: 211-217, 2013.

2. Tsukanov VV, Butorin NN, Maady AS, Shtygasheva OV, Amelchugova OS, Tonkikh JL, Fassan $M$ and Rugge $M$ : Helicobacter pylori infection, intestinal metaplasia, and gastric cancer risk in Eastern Siberia. Helicobacter 16: 107-112, 2011.

3. Chen W, Zheng R, Baade PD, Zhang S, Zeng H, Bray F, Jemal A, $\mathrm{Yu}$ XQ and He J: Cancer statistics in China, 2015. CA Cancer J Clin 66: 115-132, 2016.

4. Song Z, Wu Y, Yang J, Yang D and Fang X: Progress in the treatment of advanced gastric cancer. Tumour Biol 39: 1010428317714626, 2017.

5. Sitarz R, Skierucha M, Mielko J, Offerhaus GJA, Maciejewski R and Polkowski WP: Gastric cancer: Epidemiology, prevention, classification, and treatment. Cancer Manag Res 10: 239-248, 2018.

6. Japanese Gastric Cancer Association: Japanese gastric cancer treatment guidelines 2014 (ver. 4). Gastric Cancer 20: 1-19, 2017.

7. Chon SH, Berlth F, Plum PS, Herbold T, Alakus H, Kleinert R, Moenig SP, Bruns CJ, Hoelscher AH and Meyer HJ: Gastric cancer treatment in the world: Germany. Transl Gastroenterol Hepatol 2: 53, 2017.

8. Kang CB, Hong Y, Dhe-Paganon S and Yoon HS: FKBP family proteins: Immunophilins with versatile biological functions Neurosignals 16: 318-325, 2008.

9. Coss MC, Winterstein D, Sowder RC II and Simek SL: Molecular cloning, DNA sequence analysis, and biochemical characterization of a novel 65-kDa FK506-binding protein (FKBP65). J Biol Chem 270: 29336-29341, 1995.

10. Patterson CE, Schaub T, Coleman EJ and Davis EC: Developmental regulation of FKBP65. An ER-localized extracellular matrix binding-protein. Mol Biol Cell 11: 3925-3935, 2000.

11. Ishikawa Y, Vranka J, Wirz J, Nagata K and Bachinger HP: The rough endoplasmic reticulum-resident FK506-binding protein FKBP65 is a molecular chaperone that interacts with collagens. J Biol Chem 283: 31584-31590, 2008.
12. Staab-Weijnitz CA, Fernandez IE, Knüppel L, Maul J, Heinzelmann K, Juan-Guardela BM, Hennen E, Preissler G, Winter H, Neurohr C, et al: FK506-binding protein 10, a potential novel drug target for idiopathic pulmonary fibrosis. Am J Respir Crit Care Med 192: 455-467, 2015.

13. Knüppel L, Heinzelmann K, Lindner M, Hatz R, Behr J, Eickelberg O and Staab-Weijnitz CA: FK506-binding protein 10 (FKBP10) regulates lung fibroblast migration via collagen VI synthesis. Respir Res 19: 67, 2018.

14. Solassol J, Mange A and Maudelonde T: FKBP family proteins as promising new biomarkers for cancer. Curr Opin Pharmacol 11: 320-325, 2011.

15. Yao YL,Liang YC, Huang HH and Yang WM: FKBPs in chromatin modification and cancer. Curr Opin Pharmacol 11: 301-307, 2011.

16. Quinn MC, Wojnarowicz PM, Pickett A, Provencher DM, Mes-Masson AM, Davis EC and Tonin PN: FKBP10/FKBP65 expression in high-grade ovarian serous carcinoma and its association with patient outcome. Int J Oncol 42: 912-920, 2013.

17. Henriksen R, Sørensen FB, Ørntoft TF and BirkenkampDemtroder K: Expression of FK 506 binding protein 65 (FKBP65) is decreased in epithelial ovarian cancer cells compared to benign tumor cells and to ovarian epithelium. Tumour Biol 32: 671-676, 2011.

18. Ramadori G, Konstantinidou G, Venkateswaran N, Biscotti T, Morlock L, Galié M, Williams NS, Luchetti M, Santinelli A, Scaglioni PP and Coppari R: Diet-induced unresolved ER stress hinders KRAS-driven lung tumorigenesis. Cell Metab 21: $117-125,2015$.

19. Paulo P, Ribeiro FR, Santos J, Mesquita D, Almeida M, Barros-Silva JD, Itkonen H, Henrique R, Jerónimo C, Sveen A, et al: Molecular subtyping of primary prostate cancer reveals specific and shared target genes of different ETS rearrangements. Neoplasia 14: 600-611, 2012.

20. Sun Z, Dong J, Zhang S, Hu Z, Cheng K, Li K, Xu B, Ye M, Nie Y, Fan D and Zou H: Identification of chemoresistance-related cell-surface glycoproteins in leukemia cells and functional validation of candidate glycoproteins. J Proteome Res 13: 1593-1601, 2014.

21. Ge Y, Xu A, Zhang M, Xiong H, Fang L, Zhang X, Liu C and Wu S: FK506 binding protein 10 is overexpressed and promotes renal cell carcinoma. Urol Int 98: 169-176, 2017.

22. Olesen SH, Christensen LL, Sørensen FB, Cabezón T, Laurberg S, Orntoft TF and Birkenkamp-Demtröder K: Human FK506 binding protein 65 is associated with colorectal cancer. Mol Cell Proteomics 4: 534-544, 2005.

23. Wu JG, Wang JJ, Jiang X, Lan JP, He XJ, Wang HJ, Ma YY, Xia YJ, $\mathrm{Ru}$ GQ, Ma J, et al: MiR-125b promotes cell migration and invasion by targeting PPP1CA-Rb signal pathways in gastric cancer, resulting in a poor prognosis. Gastric Cancer 18: 729-739, 2015.

24. Imaoka H, Toiyama Y, Okigami M, Yasuda H, Saigusa S, Ohi M, Tanaka K, Inoue Y, Mohri Y and Kusunoki M: Circulating microRNA-203 predicts metastases, early recurrence, and poor prognosis in human gastric cancer. Gastric Cancer 19: 744-753, 2016.

25. Liang M, Shi B, Liu J, He L, Yi G, Zhou L, Yu G and Zhou X: Downregulation of miR203 induces overexpression of PIK3CA and predicts poor prognosis of gastric cancer patients. Drug Des Devel Ther 9: 3607-3616, 2015.

26. Leek JT, Johnson WE, Parker HS, Fertig EJ, Jaffe AE, Storey JD, Zhang Y and Torres LC: sva: Surrogate variable analysis. $\mathrm{R}$ package version 3.32.1,2019.

27. Huang WY, Hsu SD, Huang HY, Sun YM, Chou CH, Weng SL and Huang HD: MethHC: A database of DNA methylation and gene expression in human cancer. Nucleic Acids Res 43: D856-D861,2015.

28. Tang Z, Li C, Kang B, Gao G, Li C and Zhang Z: GEPIA: A web server for cancer and normal gene expression profiling and interactive analyses. Nucleic Acids Res 45: W98-W102, 2017.

29. Szász AM, Lánczky A, Nagy Á, Förster S, Hark K, Green JE, Boussioutas A, Busuttil R, Szabó A and Győrffy B: Cross-validation of survival associated biomarkers in gastric cancer using transcriptomic data of 1,065 patients. Oncotarget 7: 49322-49333, 2016.

30. Uhlén M, Fagerberg L, Hallström BM, Lindskog C, Oksvold P, Mardinoglu A, Sivertsson Å, Kampf C, Sjöstedt E, Asplund A, et al: Proteomics. Tissue-based map of the human proteome. Science 347: 1260419, 2015.

31. Yang S, Kim CY, Hwang S, Kim E, Kim H, Shim H and Lee I: COEXPEDIA: Exploring biomedical hypotheses via co-expressions associated with medical subject headings (MeSH). Nucleic Acids Res 45: D389-D396, 2017. 
32. Romano S, D'Angelillo A and Romano MF: Pleiotropic roles in cancer biology for multifaceted proteins FKBPs. Biochim Biophys Acta 1850: 2061-2068, 2015.

33. Christiansen HE, Schwarze U, Pyott SM, AlSwaid A, Al Balwi M, Alrasheed S, Pepin MG, Weis MA, Eyre DR and Byers PH: Homozygosity for a missense mutation in SERPINH1, which encodes the collagen chaperone protein HSP47, results in severe recessive osteogenesis imperfecta. Am J Hum Genet 86: 389-398, 2010.

34. Essawi O, Symoens S, Fannana M, Darwish M, Farraj M, Willaert A, Essawi T, Callewaert B, De Paepe A, Malfait F and Coucke PJ: Genetic analysis of osteogenesis imperfecta in the Palestinian population: Molecular screening of 49 affected families. Mol Genet Genomic Med 6: 15-26, 2018.

35. Chen Y, Terajima M, Banerjee P, Guo H, Liu X, Yu J, Yamauchi M and Kurie JM: FKBP65-dependent peptidyl-prolyl isomerase activity potentiates the lysyl hydroxylase 2-driven collagen cross-link switch. Sci Rep 7: 46021, 2017.

36. Gjaltema RA, van der Stoel MM, Boersema M and Bank RA: Disentangling mechanisms involved in collagen pyridinoline cross-linking: The immunophilin FKBP65 is critical for dimerization of lysyl hydroxylase 2. Proc Natl Acad Sci USA 113: 7142-7147, 2016.

37. Duran I, Martin JH, Weis MA, Krejci P, Konik P, Li B, Alanay Y, Lietman C, Lee B, Eyre D, et al: A chaperone complex formed by HSP47, FKBP65, and BiP modulates telopeptide Lysyl hydroxylation of type I procollagen. J Bone Miner Res 32: 1309-1319, 2017.
38. Vollmann EH, Cao L, Amatucci A, Reynolds T, Hamann S, Dalkilic-Liddle I, Cameron TO, Hossbach M, Kauffman KJ, Mir FF, et al: Identification of novel fibrosis modifiers by in vivo siRNA silencing. Mol Ther Nucleic Acids 7: 314-323, 2017.

39. Hagedorn M, Siegfried G, Hooks KB and Khatib AM: Integration of zebrafish fin regeneration genes with expression data of human tumors in silico uncovers potential novel melanoma markers. Oncotarget 7: 71567-71579, 2016.

40. Rahim S, Minas T, Hong SH, Justvig S, Celik H, Kont YS, Han J, Kallarakal AT, Kong Y, Rudek MA, et al: A small molecule inhibitor of ETV1, YK-4-279, prevents prostate cancer growth and metastasis in a mouse xenograft model. PLoS One 9: e114260, 2014

41. Heard ME, Besio R, Weis M, Rai J, Hudson DM, Dimori M, Zimmerman SM, Kamykowski JA, Hogue WR, Swain FL, et al: Sc65-Null mice provide evidence for a novel endoplasmic reticulum complex regulating collagen Lysyl hydroxylation. PLoS Genet 12: e1006002, 2016.

This work is licensed under a Creative Commons Attribution-NonCommercial-NoDerivatives 4.0 International (CC BY-NC-ND 4.0) License. 